\title{
Time-Domain Electromagnetic Soundings to Characterize Water Quality Within a Freshwater/Saline-Water Transition Zone, Estancia Valley, New Mexico, July 2005-A Reconnaissance Study
}

During July 2005, the U.S. Geological Survey, in cooperation with the New Mexico Bureau of Geology and Mineral Resources, conducted a reconnaissance study in the Estancia Valley in central New Mexico (fig. 1) to characterize water

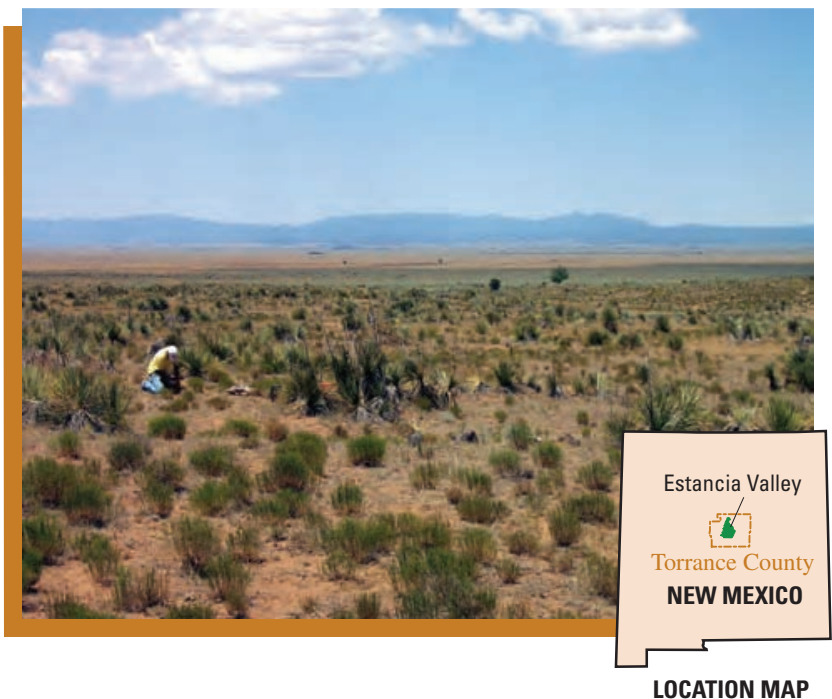

Figure 1. Study area of the Estancia Valley, New Mexico.

quality using time-domain electromagnetic (TDEM) surface-geophysical soundings. TDEM sounding (Fitterman and Labson, 2005) is one of a number of surfacegeophysical methods that provide a relatively quick and inexpensive means to characterize subsurface geologic and hydrogeologic properties. TDEM surfacegeophysical methods can be used to detect variations in the electrical resistivity of the subsurface, which in turn can be related to variations in the physical and chemical properties of soil, rock, and pore fluids.

Seven TDEM soundings were collected along an east-southeasterly profile about 24 kilometers long (fig. 2) in which apparent electrical resistivity was measured

\section{LOCATION MAP}

to depths of about 80 meters. This report briefly describes the hydrogeologic setting, how TDEM soundings work, the methods of data acquisition and processing, inversion modeling, and modeling interpretation and findings. The interpretation involves characterizing water quality on the basis of geologic characteristics and resistivities.

\section{Hydrogeologic Setting}

The study area encompasses about 525 square kilometers in the Estancia Valley in central New Mexico. Altitudes in the study area range from about 2,300 meters along the western edge of the area to about 1,900 meters along the north-south central axis of the study area, where a series of playas are incised into the valley floor (Bachhuber, 1982).

The study area is composed of deformed Paleozoic and Mesozoic rocks overlain by Cenozoic (Quaternary) sediment (Smith, 1957; Hawley and Hernandez, 2003). Figure 3 shows a conceptual geologic section along the TDEM profile. Paleozoic- and Mesozoic-age strata generally dip eastward (except for a trough centered at about 9,000 meters from the

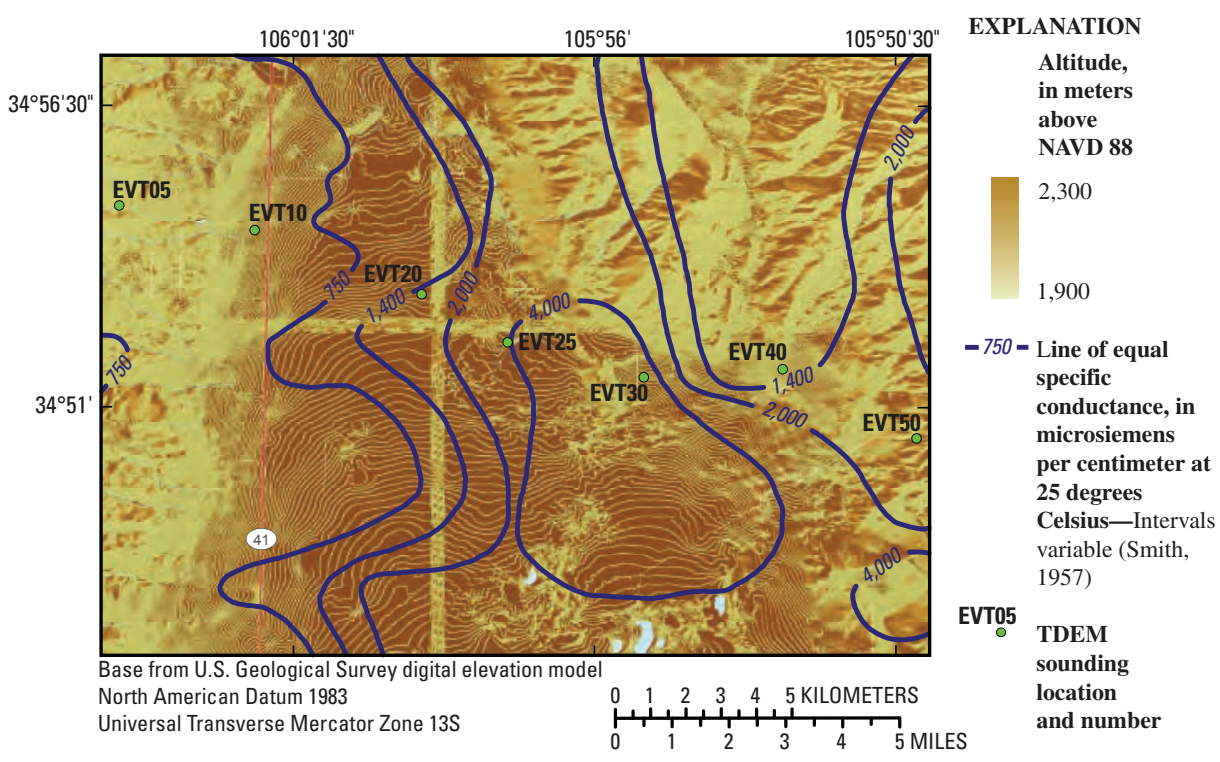

Figure 2. Time-domain electromagnetic (TDEM) sounding sites, July 2005, and lines of equal specific conductance, fall 1957, Estancia Valley study area, New Mexico. 
ALTITUDE， WEST IN METERS

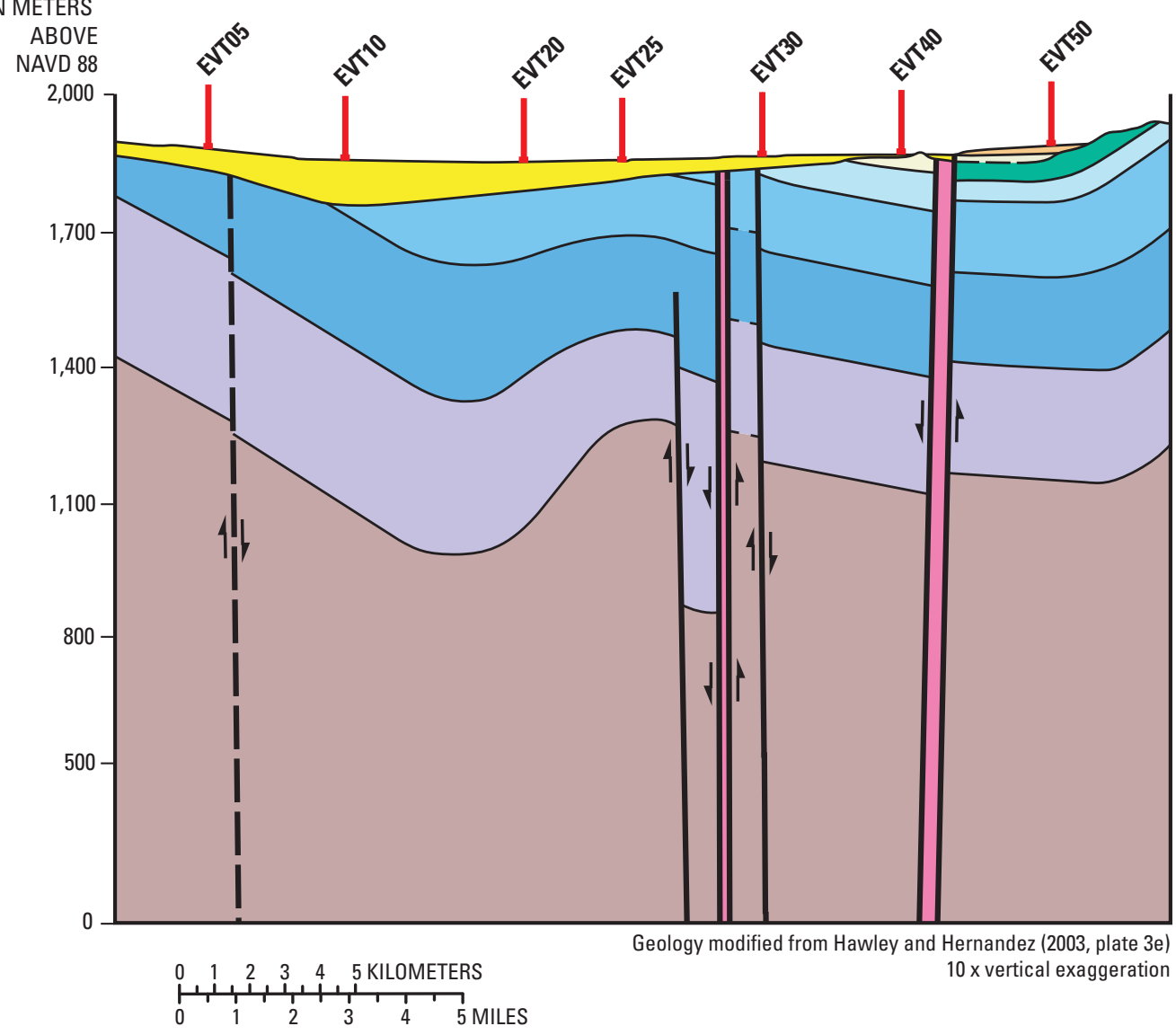

EXPLANATION

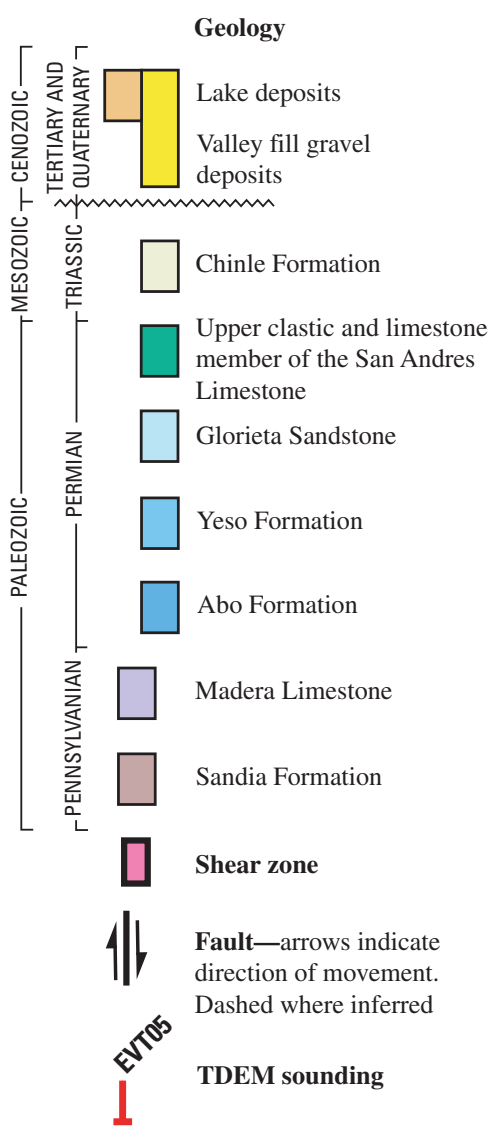

Figure 3. Conceptual model of subsurface geology and time-domain electromagnetic (TDEM) sounding locations, Estancia Valley study area, New Mexico.

west end of the section), and Quaternary sediment overlies progressively younger strata from west to east. The early Pennsylvanian-age Sandia Formation is overlain by the middleto-late Pennsylvanian-age Madera Limestone. The Madera Limestone is capable of producing large quantities of freshwater (specific conductance less than about 1,700 microsiemens per centimeter at 25 degrees Celsius $[\mu \mathrm{S} / \mathrm{cm}]$ ) (Hawley and Hernandez, 2003). Overlying the Madera Limestone are the Permian-age Abo and Yeso Formations and Glorieta Sandstone. The Yeso Formation and Glorieta Sandstone can contain slightly to moderately saline water (specific conductance about 1,700 to $5,000 \mu \mathrm{S} / \mathrm{cm}$ ) (Smith, 1957). The Permian-age San Andres Limestone and Triassic-age Chinle Formation unconformably overlie the Glorieta Sandstone. The erosional surface of the Paleozoic and Mesozoic strata forms an angular unconformity that is overlain by Quaternary valley fill deposits, which thin from west to east, and lake deposits along the eastern margin of the study area. The valley fill and lake deposits contain freshwater to slightly saline water. Faults and fractures characterize the subsurface, particularly the Madera Limestone, Yeso Formation, and Glorieta Sandstone (Smith, 1957).

Average rainfall in the area is about 32 centimeters per year. Because the Estancia Valley is a topographically closed basin, the principal means of discharge for precipitation that falls within the basin is evapotranspiration.

The dissolved mineral content of ground water in the valley fill deposits increases from west to east (Smith, 1957). In the western part of the study area, the water quality generally is satisfactory for irrigation, stock, and domestic and community water supply. To the east, water quality rapidly deteriorates and generally is unsatisfactory for irrigation or human consumption, although it is still used for watering livestock. The historical lateral transition between freshwater and slightly saline water along the profile in the valley fill deposits (fig. 2) is relatively sharp, occurring over a distance of less than about 2 kilometers.

\section{How Time-Domain Electromagnetic Soundings Work}

Electromagnetic measurements are made by transmitting an alternating current into a square loop of insulated wire deployed on the land surface. The current consists of equal periods of time-on and time-off base frequencies (North Carolina Division of Water Resources, 2004) that produce a primary electromagnetic field in the immediate vicinity of the wire loop. Termination of the current flow is not instantaneous, but occurs over a period of a few microseconds, known as the ramp time, during which the magnetic field is time-variant. The time-variant nature of the primary electromagnetic field creates a secondary electromagnetic field in the ground beneath the loop. This secondary field immediately begins to decay, in the process generating additional eddy currents (fig. 4) that propagate downward and outward into the subsurface like a series of smoke rings. The secondary currents are measured by a receiver located in the center of the transmitter loop only during the time-off period. The depth of investigation depends 
on the time interval after shutoff of the current, because at later times, the receiver is sensing eddy currents at progressively greater depths. The intensity of the eddy currents at specific times and depths is determined by the combined conductivity of the subsurface rock and fluid (Stewart and Gay, 1986).

\section{Data Acquisition}

Seven sounding sites were selected to provide a uniform distribution of data to determine variations in electrical properties across the study area. A Geonics Protem-47 system (fig. 5A) using a 60- by 60-meter square transmitter loop (Tx) was used to collect the TDEM soundings (Geonics Ltd., 2005).

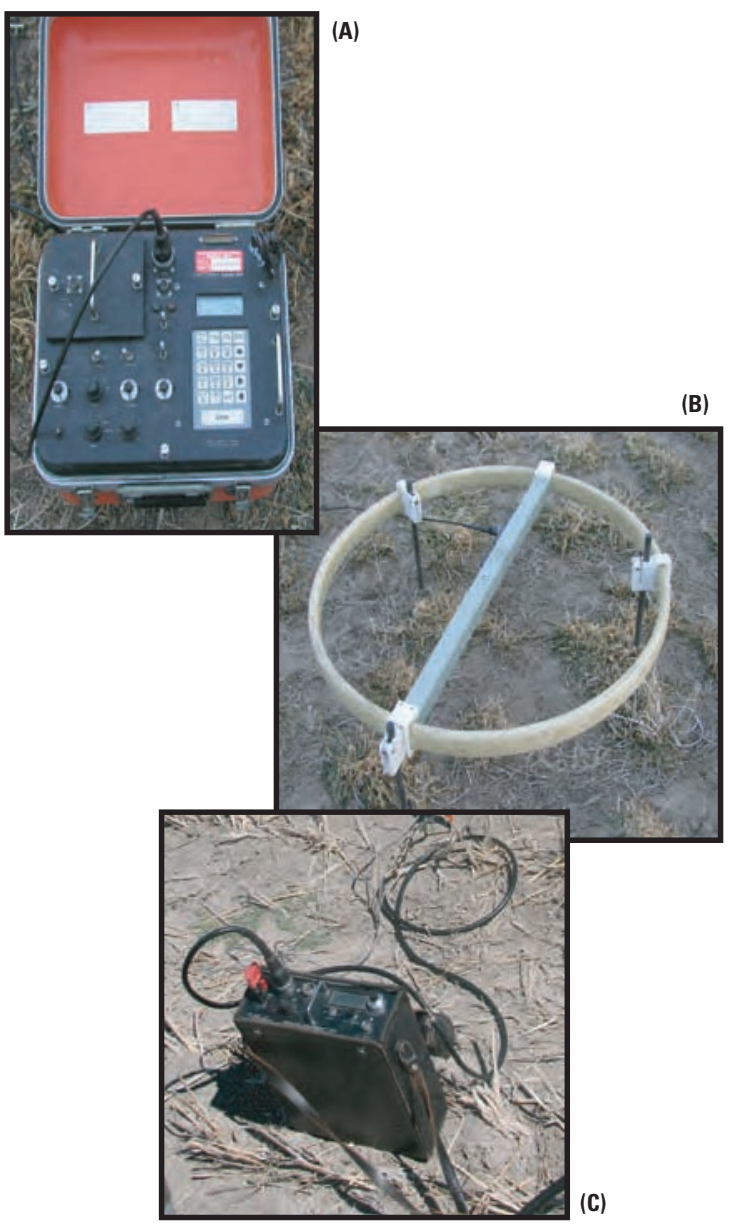

Figure 5. Time-domain electromagnetic sounding equipment used in the Estancia Valley study area, New Mexico: (A) Protem-47 system, (B) transmitter loop, and (C) Protem-47 transmitter.
A 1-meter-diameter multi-turn loop receiver $(\mathrm{Rx})$ with a 31.4-square-meter area measured magnetic fields at the center of the transmitter loop (fig. 5B).

The Protem-47 Tx transmitter (fig. 5C) used an injection current ranging from 2.3 to 3.5 amps for the various soundings. Three frequencies were used to collect voltage data, with preset base frequencies of 315 hertz [ultra-high], 75 hertz [very-high], and 30 hertz [high] configured in the Protem TDEM unit. The Rx unit samples signal amplitudes in 20 subintervals (gates) during each measuring step, averaging the signal amplitudes in each gate over a specified number of duty cycles (eight in this application). The 20 gate widths are distributed exponentially over a measuring interval in each step of 0.8 millisecond (ultra-high range), 3.0 millisecond (very-high range), and 8.0 millisecond (high range). The Rx was set to collect three measurements of voltage for each base frequency.

\section{Data Processing}

For each sounding, the voltage data were averaged and evaluated statistically using NTEMAVG v. 3.04, a computer program written by David V. Fitterman (U.S. Geological Survey, written commun., 2006). Using this program, the raw field data (voltage data) were first averaged to reduce error; then the averaged data were used to estimate uncertainty by calculating the standard deviation of the voltage; and finally, the apparent resistivity of each gate for each frequency was calculated. Voltages that yielded a standard deviation greater than about 3 percent were not used, which eliminated data from later-time gates that yielded the highest noise. Figure 6 illustrates the percentage standard deviation of the average voltages from the ultra-high-, very-high-, and high-frequency data. The ultra-high-frequency data yielded the lowest standard deviation through all 20 gates. In the very-high-frequency data, standard deviations increased sharply after the 14th gate, whereas in the high-frequency data, standard deviations increased sharply after the sixth gate. The amplitude of the recorded voltage decayed below electromagnetic noise level at lower (very-high and high) frequencies because the power of the Tx did not induce a large enough magnetic field to be measured accurately during later times.

\section{Inverse Modeling}

IX1D, a program developed by Interpex Ltd. (2006), was used to visually analyze the apparent resistivity data calculated by NTEMAVG. The apparent resistivity data were plotted as a function of time on a log scale. Data points that deviated 
severely (a judgment decision) from the curve were deleted before inverse modeling. Inverse modeling, using the smooth modeling technique based on Occam's inversion principle (Constable and others, 1987), was used to estimate the geologic or hydrogeologic structure for each sounding along the profile. The IX1D defaults were used for all smooth-modeling parameters except the number of modeling units, which was set to 30 with the first layer of units starting at 1 meter. A multiple-iteration, smooth-model inversion was computed until the root-mean-square error reached an acceptable limit of about 5 percent or less. The smooth-model inversion technique minimizes model roughness subject to the constraint that the model fits the data to a desired tolerance (Interpex Ltd., 2006).

\section{Modeling Interpretation and Findings}

The smooth-model inversion results of each sounding collected in the study area produced models at each sounding site with similar resistor, conductor, and resistor resistivity structure. To depict the spatial changes in resistivity based on the smooth-model inversion results, a two-dimensional profile of the TDEM soundings with superimposed faults (Hawley and Hernandez, 2003) was created (fig. 7).

The principal finding of this study is the potential relation between faulting and the occurrence of freshwater and slightly saline water, based on the configuration of resistivity along the TDEM profile. A low-resistivity zone along the profile

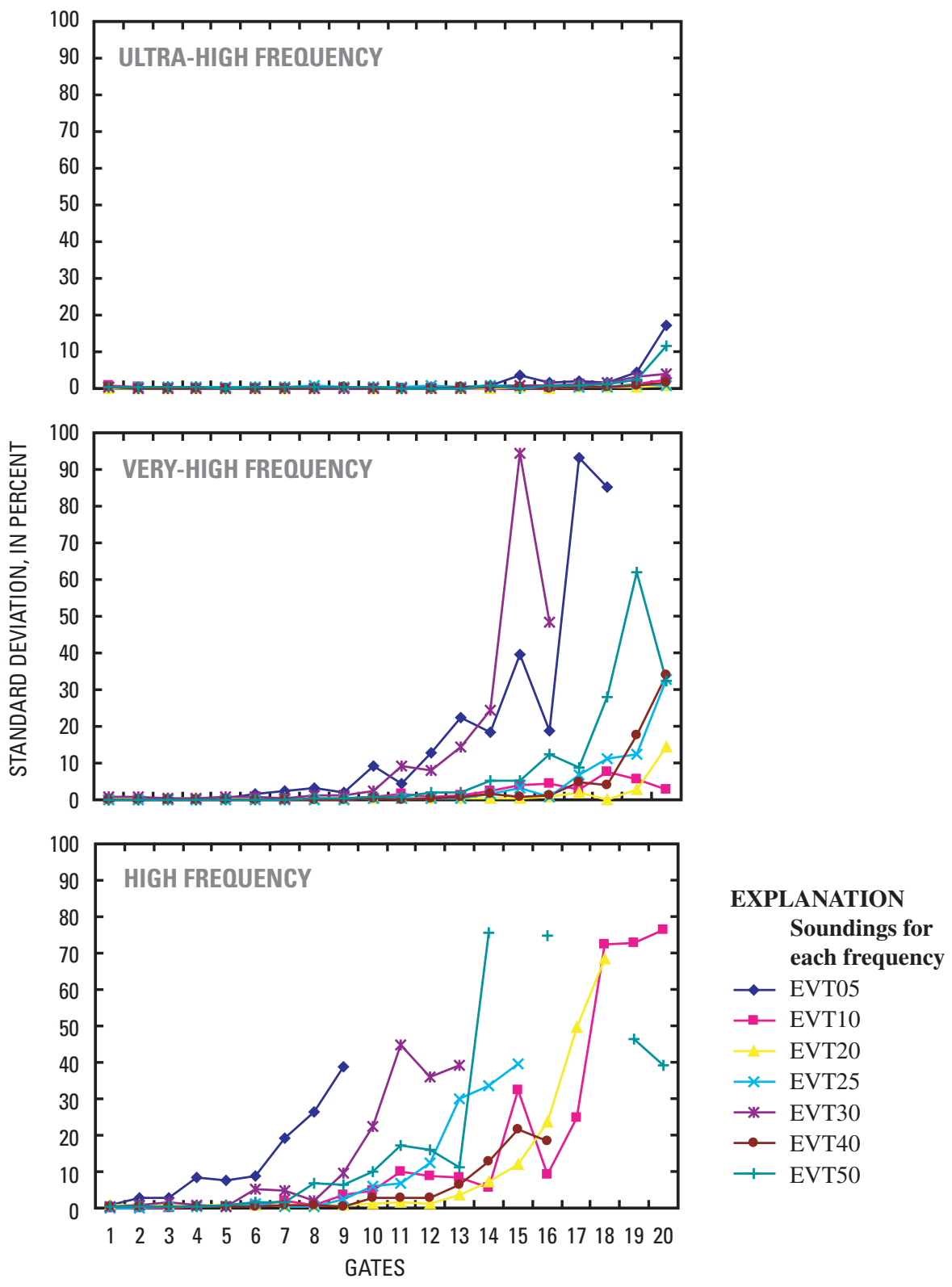

Figure 6. Percentage standard deviation of the average voltages of the ultra-high-, very-high-, and high-frequency data collected from time-domain electromagnetic soundings, Estancia Valley study area, New Mexico. 


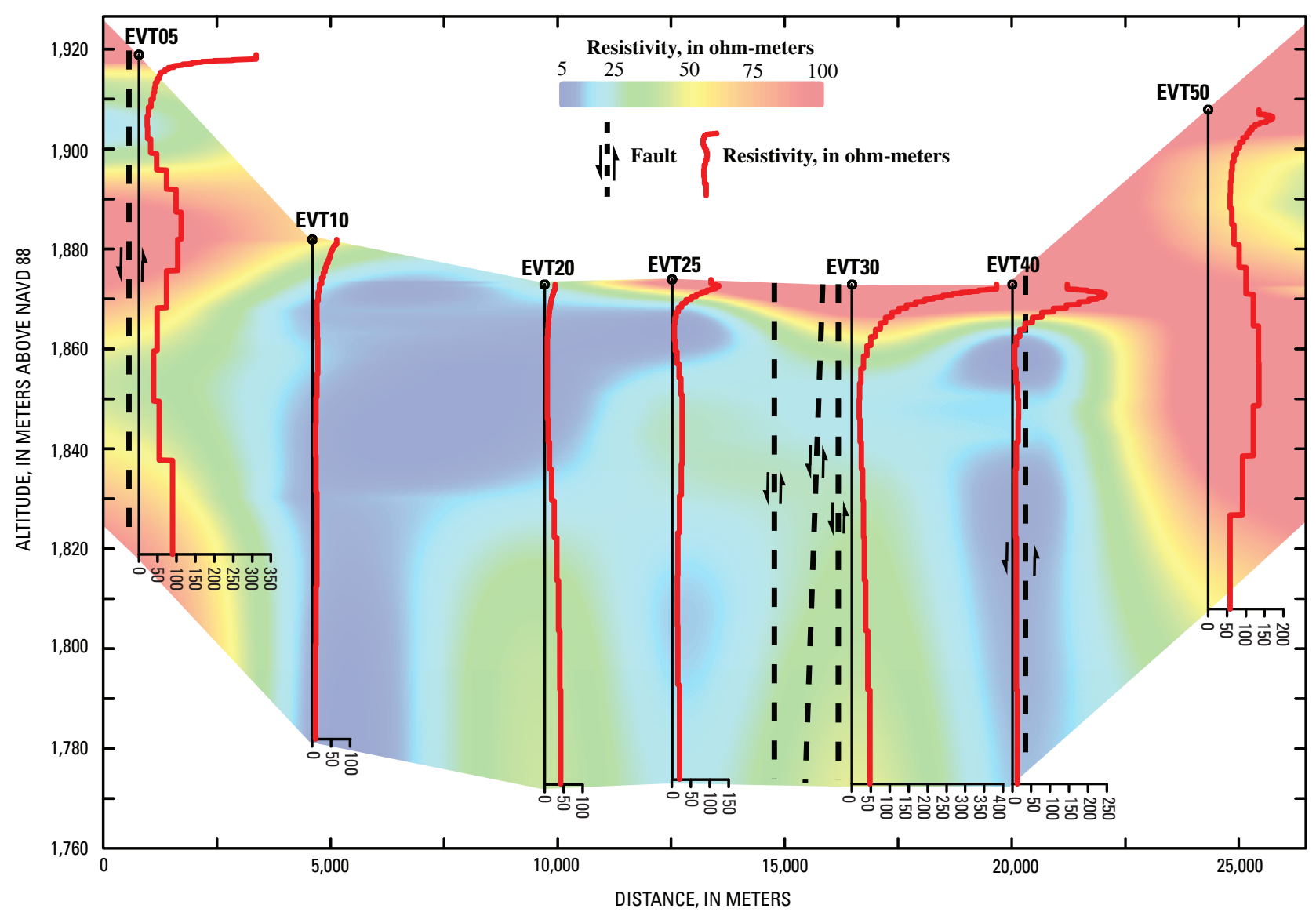

Figure 7. Two-dimensional section showing resistivity distribution based on the smooth-model inversion results with superimposed faults, Estancia Valley study area, New Mexico.

(resistivity ranging from greater than 0 to 10 ohm-meters) occurs between sites EVT10 and EVT20. The western part of this low-resistivity zone extends to the base of the profile. The occurrence of this zone cannot be interpreted on the basis of known geologic characteristics. Another low-resistivity zone is indicated near EVT40 below an altitude of about 1,865 meters above NAVD 88. Faults near EVT40 could provide preferential flow paths for upward movement of slightly saline water from the Yeso Formation and Glorieta Sandstone, which could account for the relatively low subsurface resistivities. A sharp

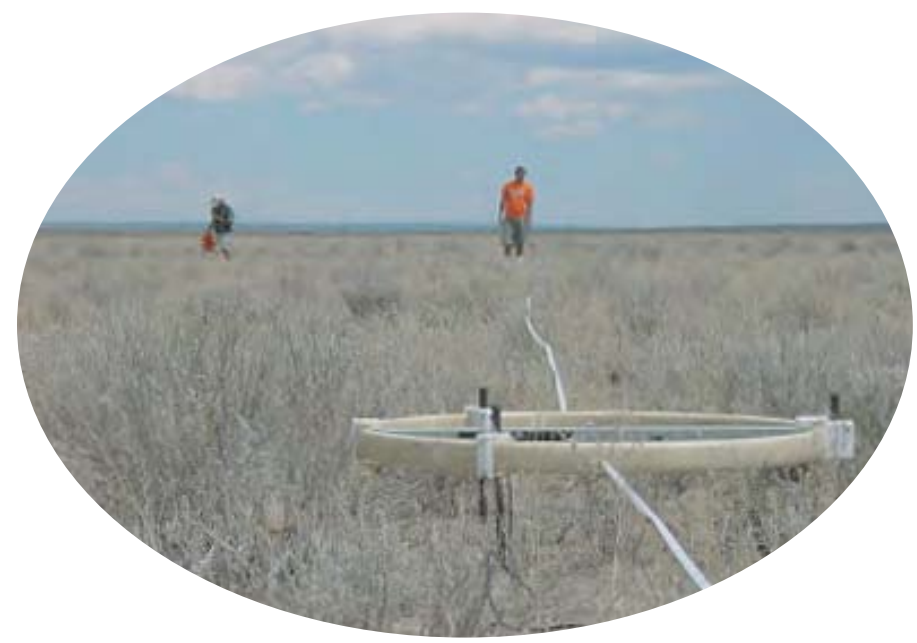

conductive/resistive boundary (interface) from greater than 0 to $50 \mathrm{ohm}$-meters appears at EVT25 and marks the beginning of a high-resistivity, near-surface zone that extends laterally through EVT40. Faults near EVT30 could provide preferential flow paths for upward movement of freshwater from the Madera Limestone, which could account for the high resistivities in that zone.

To adequately define the relations between subsurface resistivity measured by TDEM methods and spatial changes in water quality, additional water-quality, geology, and borehole-geophysical data are needed. The low-resistivity zones at the base of the profile beneath EVT10 and EVT40 might be defined less accurately than they could have been had a more powerful transmitter been used, probably in conjunction with a loop size larger than 60 by 60 meters.

\section{—Sachin D. Shah ${ }^{1}$, Wade H. Kress ${ }^{1}$, and Lewis A. Land ${ }^{2}$}

\footnotetext{
${ }^{1}$ U.S. Geological Survey.

${ }^{2}$ New Mexico Bureau of Geology and Mineral Resources.
} 


\section{References Cited}

Bachhuber, F.W., 1982, Quaternary history of the Estancia Valley, central New Mexico: New Mexico Geological Society, Guidebook 33, p. 343-346.

Constable, S.C., Parker, R.L., and Constable, C.G., 1987, Occam's inversion-A practical algorithm for generating smooth models from EM sounding data: Geophysics, v. 52, p. 289-300.

Fitterman, D.V., and Labson, V.F., 2005, Electromagnetic induction methods for environmental problems, in Butler, D.K., ed., Near-surface geophysics-Part 1. Concepts and fundamentals: Tulsa, Society of Exploration Geophysics, p. 295-349.

Geonics Ltd., 2005, TEM-57 transmitter, accessed August 1, 2005, at http://www.geonics.com/html/tem57-mk2.html

Hawley, J.W., and Hernandez, J.W., 2003, A new perspective on the hydrogeologic framework and brackish-groundwater resources of the eastern Estancia Basin, central New Mexico, in Second New Mexico Symposium on Hydrologic Modeling, New Mexico Tech, August 12, 2003: Symposium Program, p. E-25.

Interpex Ltd., 2006, IX1D v. 3 inversion software, accessed June 2006 at http://www.interpex.com/SoftwareIndex.htm

North Carolina Division of Water Resources, 2004, Time domain electromagnetic geophysics, accessed July 31, 2006 , at http://www.ncwater.org/Education_and_Technical_ Assistance/Ground_Water/TDEM/.

Smith, R.E., 1957, Geology and ground-water resources of Torrance County, New Mexico: State Bureau of Mines and Mineral Resources Ground-Water Report 5, 186 p.

Stewart, M., and Gay, M.C., 1986, Evaluation of transient electromagnetic soundings for deep detection of conductive fluids: Ground Water, v. 24, p. 351-356.
Vertical coordinate information is referenced to the North American Vertical Datum of 1988 (NAVD 88).

Horizontal coordinate information is referenced to the North American Datum of 1983 (NAD 83).

Any use of trade, product, or firm names is for descriptive purposes only and does not imply endorsement by the U.S. Government.

\section{For additional information contact:}

Director

E-mail: dc_tx@usgs.gov

USGS Texas Water Science Center Phone: (512) 927-3500

8027 Exchange Dr.

Austin, TX 78754-4733
FAX: (512)927-3590

World Wide Web:

http://tx.usgs.gov/

\section{This fact sheet is based on the journal article:}

Shah, S.D., and Kress, W.H., in press, Time-domain electromagnetic soundings to characterize water quality within a freshwater/saline-water transition zone, Estancia Valley, New Mexico, USA - A reconnaissance study: Association of Exploration Geophysicists, India Journal of Geophysics, v. XXVIII. 